\title{
Effect of $\mathrm{Bi}^{3+}$ Ion Substitution on Magnetic Properties of Cobalt Nano Ferrites Prepared by Sol-Gel Combustion Method
}

\author{
Naraavula Suresh Kumar ${ }^{1}$, Katrapally Vijaya Kumar ${ }^{2 *}$ \\ ${ }^{1}$ Mallareddy Institute of Engineering \& Technology, Secunderabad, TS, India \\ ${ }^{2}$ Department of Physics, JNTUH College of Engineering Jagtial, Nachupally, Karimnagar-Dist, TS, India \\ Email: "kvkphd@gmail.com
}

Received 22 May 2016; accepted 24 July 2016; published 27 July 2016

Copyright (C) 2016 by authors and Scientific Research Publishing Inc.

This work is licensed under the Creative Commons Attribution International License (CC BY).

http://creativecommons.org/licenses/by/4.0/

(c) () Open Access

\section{Abstract}

Bismuth substituted cobalt nano ferrites with the chemical composition $\mathrm{Co} \mathrm{Bi}_{\mathrm{x}} \mathrm{Fe}_{2-\mathrm{x}} \mathrm{O}_{4}(\mathrm{x}=0.00$, $0.05,0.10,0.15,0.20 \& 0.25$ ) were prepared by sol-gel combustion method. The phase identification of prepared samples is characterised by X-ray powder diffraction (XRD) method, which confirms the formation of a single phase fcc spinal structure. The mean crystallite sizes of all prepared samples were obtained within the range of $21( \pm 5) \mathrm{nm}$. Transmission Electron Microscopy (TEM) images also confirmed the crystallite size of all the synthesised samples was in nano range. With the effect of $\mathrm{Bi}^{3+}$ ion substitution on spinal cobalt ferrite, the magnetic properties were investigated by using Vibration Sample Magnetometer (VSM). The obtained hysteresis (M-H) curves of all the samples were analysed under the applied magnetic field of range $\pm 10 \mathrm{~K} 0 \mathrm{e}$ at $300 \mathrm{~K}$. The magnetic properties such as saturation magnetisation $\left(M_{s}\right)$, remnant magnetization $\left(M_{r}\right)$ and coercivity $\left(\mathrm{H}_{c}\right)$ values are tabulated, which show a decrease in trend as the bismuth ion concentration increases. This is due to the addition of $\mathrm{Bi}^{3+}$ ion in the place of $\mathrm{Fe}^{3+}$ ion (octahedral site) and hence the $\mathrm{Bi}^{3+}-\mathrm{Fe}^{3+}$ ion interaction predominates as compared with the $\mathrm{Fe}^{2+}-\mathrm{Fe}^{3+}$ ion interaction. The data obtained from magnetic studies, the variation among the magnetic properties have been investigated for all the prepared samples.

\section{Keywords}

Bi-Co Nano Ferrites, Sol-Gel Combustion Method, TEM and VSM

\footnotetext{
${ }^{*}$ Corresponding author.
}

How to cite this paper: Kumar, N.S. and Kumar, K.V. (2016) Effect of $\mathrm{Bi}^{3+}$ Ion Substitution on Magnetic Properties of Cobalt Nano Ferrites Prepared by Sol-Gel Combustion Method. Soft Nanoscience Letters, 6, 37-44. 


\section{Introduction}

Ferrites are well-known magnetic nano particles exhibiting great physiochemical properties. Among the different nano ferrite compositions, cobalt ferrite $\left(\mathrm{CoFe}_{2} \mathrm{O}_{4}\right)$ is one of the best ferromagnetic oxides because of its unique properties such as high coercivity, moderate saturation magnetization, mechanical hardness, chemical stability and high curie's temperature $\left(\sim 520^{\circ} \mathrm{C}\right)$ with large magneto crystalline anisotropy [1]-[3]. Along with these properties, the metal oxides produce high magneto chemical interactions, and have high magnetostriction properties. With these properties, the cobalt ferrites have great importance in biomedical sensor applications [4] [5]. In order to synthesise new materials with specific properties, doping of various metal and non-metal cations in the spinal cobalt ferrite is the best method. " $\mathrm{AB}_{2} \mathrm{O}_{4}$ " is the general composed formula of spinal ferrite in which A \& B represent tetrahedral and octahedral cation sites respectively and $\mathrm{O}$ displays oxygen anion site [6] [7]. The distribution of metal cations in the spinal ferrite leads to new materials. In this point of view, the authors aim at investigating the magnetic properties of bismuth doped cobalt nanoferrites particles. It has been observed that bismuth ferrite (BFO) is the most promising multi ferroic material because of their low electrical conductivity (high resistivity), low magnetic and low dielectric losses [8] [9]. And an interesting fact is that, with a little amount of bismuth ion substituted in $\mathrm{CoFe}_{2} \mathrm{O}_{4}$ the spinal structure of ferrite will not be changed [10] [11]. Conventionally, the nano ferrite particles can be synthesised by using different methods, like co-precipitation [12], bal-milling technique [13], sol-gel method [14], ero-gel process [15], hydro thermal method [16], and solid state reaction [17]. To obtain a highly pure crystalline nano powders at relative low temperatures, the sol-gel combustion method is the suitable one [18] [19]. Hence, the present work is done to investigate the magnetic properties of bismuth doped cobalt nano ferrites synthesised by sol-gel combustion method.

\section{Characterisation}

The structural properties of synthesised nano ferrites such as phase formation and crystallanity were determined with X-ray powder diffractometer (XRD) with Phillips X-ray diffractometer (Model 3710), with $\mathrm{CuK} \alpha(\lambda=$ $1.54^{\circ} \mathrm{A}$ ) radiation at room temperature. The TEM instrument of model (Philips model CM 120) shows the images of prepared samples having clear morphology and crystallite sizes. The magnetic properties of these samples were carried out by Vibrating Sample Magnetometer (VSM) (model Lake Shore 7307) with an applied magnetic field range $\pm 10 \mathrm{KOe}$ at $300 \mathrm{~K}$.

\section{Results and Discussion}

\subsection{XRD Analysis}

Figure 1 shows the typical XRD analysis of the prepared samples which were calcinated at $600^{\circ} \mathrm{C}$. In general the XRD pattern of a pure cobalt ferrite $\left(\mathrm{CoFe}_{2} \mathrm{O}_{4}\right)$ represents eight reflection peaks in which the highest intensity reflection peak (311) exists nearly at $2 \theta=35^{\circ}$ and the obtained XRD pattern exactly matched. However, the complete XRD pattern confirms the formation of single phase cubic spinal structure. And for the composition $\mathrm{x}$ $=0.00$, the intensity peaks are indexed with the corresponding miller indices (hkl) of pure $\mathrm{CoFe}_{2} \mathrm{O}_{4}$ and there are no impurity peaks appeared. It is also observed that the spinal structure of cobalt ferrite does not alter with small amount of bismuth ion substitution [20]. The existence of additional peaks in the XRD pattern for the compositions $\mathrm{x}=0.05$ to 0.25 are indexed with the " $"$ sign in terms of bismuth as a dopent ion. And the mean crystallite size of prepared samples was evaluated for the strongest peak (311) with Debye-scherrer's Formula (1) as follows.

$$
D=\frac{0.9 \lambda}{\beta \cos \theta}
$$

where $D$ is the mean crystallite size; $\lambda$ is the wavelength of incident $\mathrm{X}$-ray beam; $\beta$ is the full width at half of the maxima (FWHM) in radians and $\theta$ is the Bragg's diffraction angle.

With analysis of these results the lattice parameters such as crystallite size (D), lattice constant (a) were increasing with the increase of doping concentration $(\mathrm{x})$. This is due to the smaller ionic radiuses of $\mathrm{Fe}^{3+}(0.64 \AA)$ ions are partially replaced by the greater ionic radius of $\mathrm{Bi}^{3+}(1.31 \AA)$ ions at octahedral position (B-site). The calculated crystallite size was found to be as $21( \pm 5) \mathrm{nm}$ and these results were well agreement with literature [21] [22]. The lattice constant of all these ferrites were evaluated by using Equation (2). Similar work was 


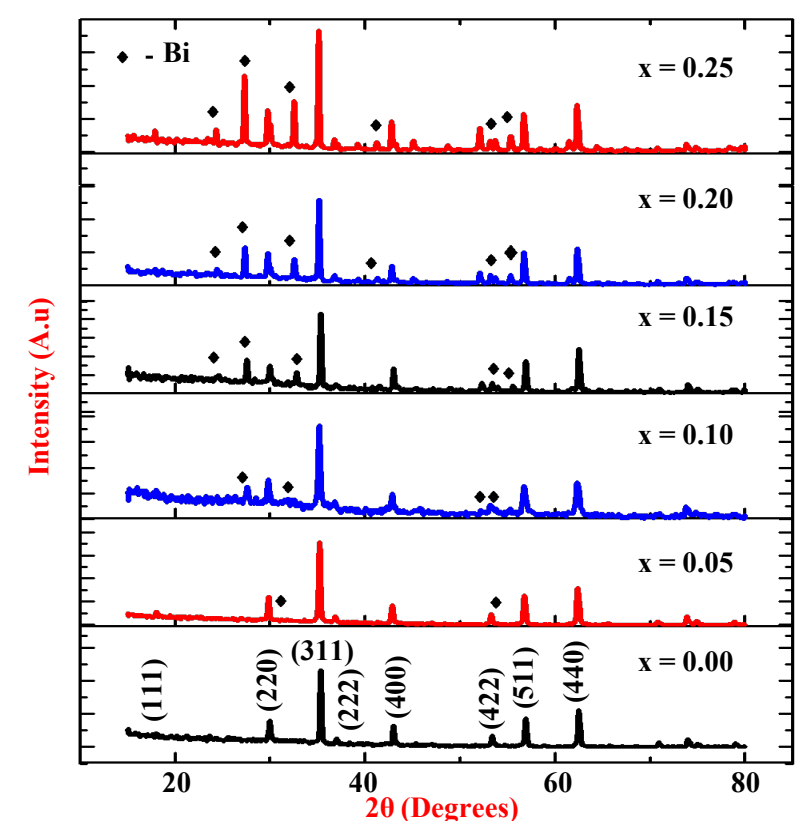

Figure 1. XRD patterns of $\mathrm{Co}_{\mathrm{Bi}_{\mathrm{x}}} \mathrm{Fe}_{2-\mathrm{x}} \mathrm{O}_{4}$ nano ferrite particles for all the compositions $(0.00 \leq \mathrm{x} \leq 0.25)$ which are sintered at $600^{\circ} \mathrm{C}$.

observed by different authors with various dopent metal ions into the spinal ferrite like $\mathrm{Cr}^{3+}, \mathrm{Zn}^{3+}, \mathrm{Mn}^{3+}$, etc. [23].

$$
a=d \sqrt{h^{2}+k^{2}+l^{2}}
$$

\subsection{Tem}

Figures 2(a)-(c) show the surface morphology and microstructure of the composition $(x=0.20)$ with Transmission Electron microscope (TEM). From the obtained TEM images, it is observed that the particles were found to be in cubic shape with less agglomeration. From Figure 2(a) and Figure 2(b), the lattice parameters such as crystallite size (D) and inter planar distance (d) are observed at different magnifications. Figure 2(c) shows the Selected Area of Electron Diffraction (SAED) patterns of the sample, which represent the most appeared intensity peaks in terms of miller indices (hkl) of different crystals in the composition. With the analysis of these images it is confirmed that, the synthesised particles are exhibiting well defined crystalline nature.

\subsection{Magnetic Properties}

Figure 3 shows a typical hysteresis loop of all the prepared compositions which are sintered at $600^{\circ} \mathrm{C}$. By using a vibrating sample magnetometer, the measurements of magnetisation for all the compositions were carried out at room temperature under the applied magnetic field of range $\pm 10 \mathrm{k}$ Oe. It is observed that, the magnetic properties such as saturation magnetisation (Ms), remnant magnetisation $(\mathrm{Mr})$ and coercivity $(\mathrm{Hc})$ values are gradually decreasing with the increase of bismuth ion concentration and the values are listed in Table 1 . The saturation magnetisation of $\mathrm{CoFe}_{2} \mathrm{O}_{4}$ sintered around $600^{\circ} \mathrm{C}$ is nearly $64 \mathrm{emu} / \mathrm{g}$, which is in good agreement with the literature values [24]. It is observed from Table 1 as the doping concentration increases in the spinal $\mathrm{CoFe}_{2} \mathrm{O}_{4}$, the saturation magnetisation decreased from $63.52-48.73 \mathrm{emu} / \mathrm{g}$. This may be attributed to the larger magnetic moment of $\mathrm{Fe}^{3+}$ ions $(5 \mu \mathrm{B})$ are partially replaced by the smaller magnetic moment of $\mathrm{Bi}^{3+}$ ions $(3 \mu \mathrm{B})$ in the octahedral site [25] [26]. Therefore the ratio of $\mathrm{Fe}^{3+}(\mathrm{B}) / \mathrm{Fe}^{3+}(\mathrm{A})$ ionic concentration was gradually decreased in the ferrite composition [27] [28]. This is due to the cation distribution in between A and B sub lattices which were proposed by Neel's two sub lattice model [29] [30]. According to this, in any ferrite the magnetic order of tetrahedral clusters (A-site) and octahedral clusters (B-site) was found to be anti parallel to each other. In this the A-A and B-B super exchange interaction was predominated by A-B super exchange interaction. So 

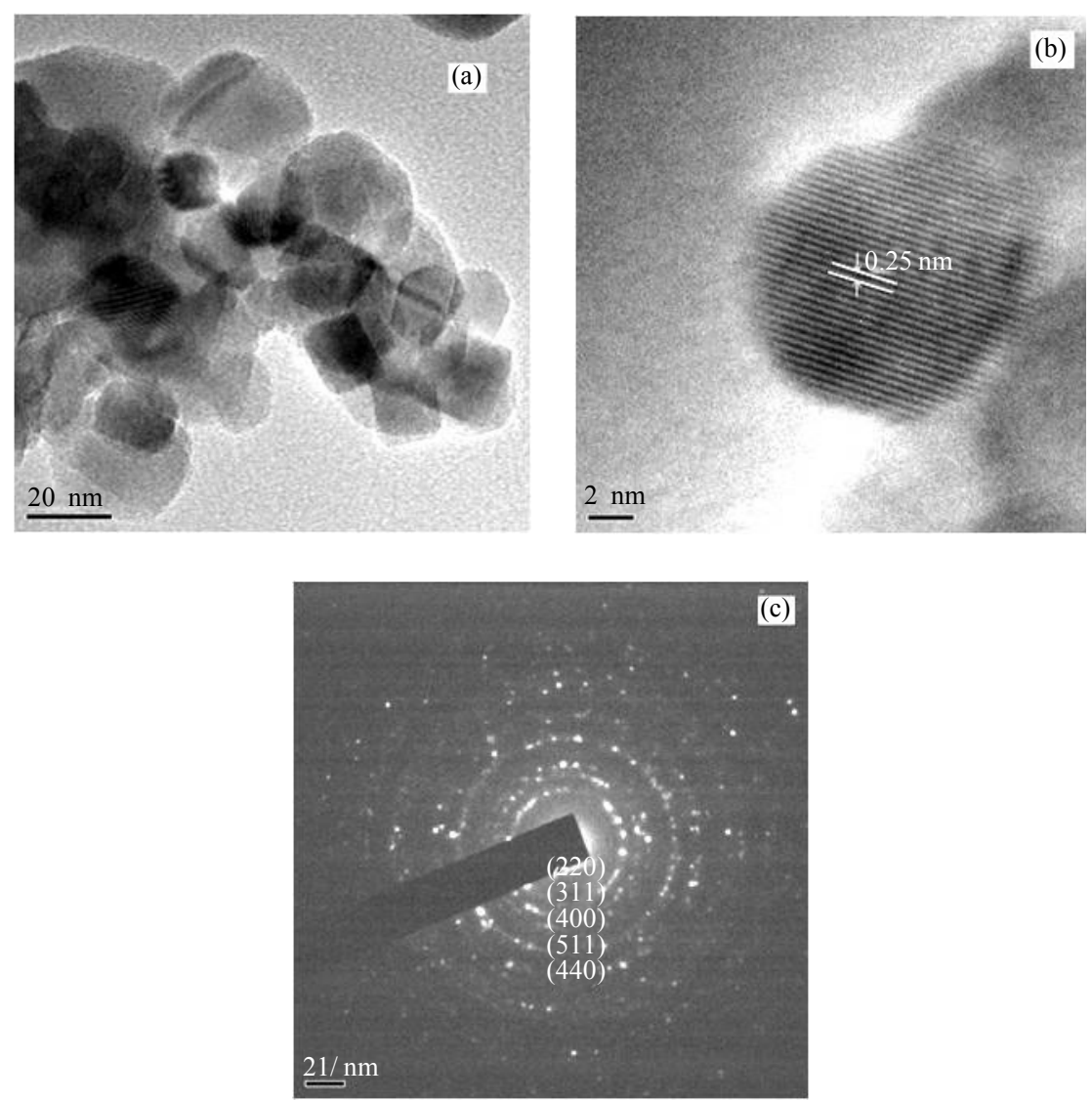

Figure 2. (a)-(b) show the low and high resolution of TEM images and (c) shows SAED pattern of the sample $\mathrm{Co} \mathrm{Bi}_{\mathrm{x}} \mathrm{Fe}_{2-\mathrm{x}} \mathrm{O}_{4}(\mathrm{x}=0.20)$ sintered at $600^{\circ} \mathrm{C}$.

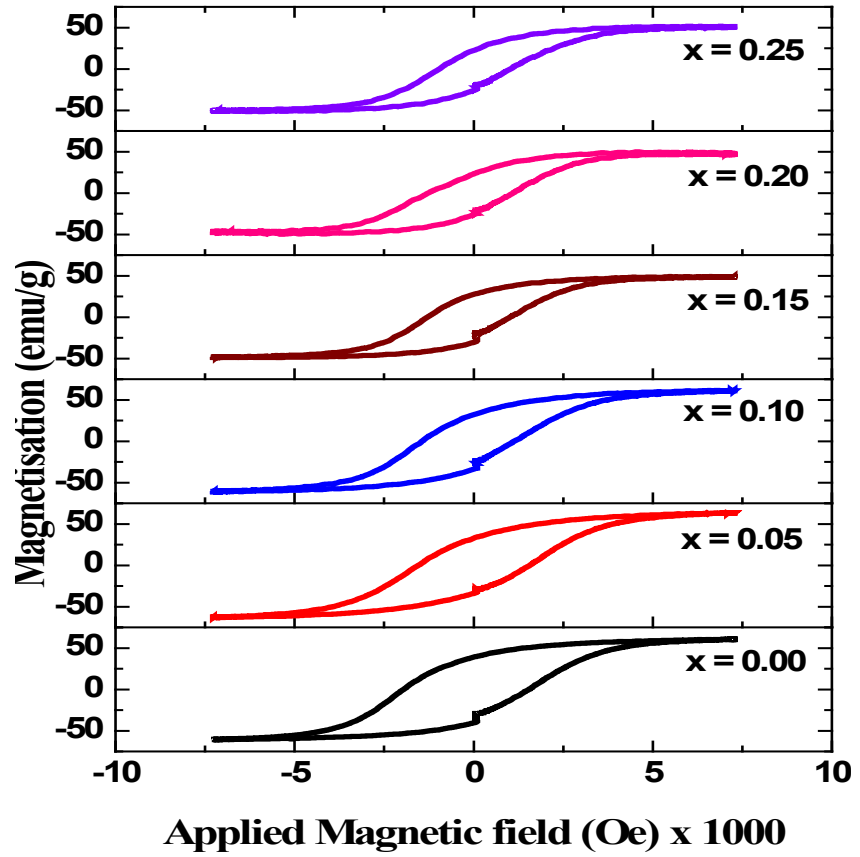

Figure 3. The room temperature hysteresis loops of bismuth substituted nano ferrites of the composition $\mathrm{CoBi}_{\mathrm{x}} \mathrm{Fe}_{2-\mathrm{x}} \mathrm{O}_{4}(0.00 \leq \mathrm{x} \leq 0.25)$ sintered at $600^{\circ} \mathrm{C}$. 
Table 1. The values of saturation magnetisation (Ms), remanent magnetisation (Mr), coercivity (Hc), anisotropy constant (K), sqareness ratio $(\mathrm{Mr} / \mathrm{Ms})$ and Bohr Magneton $\left(\mu_{\mathrm{B}}\right)$ and of $\mathrm{CoBi}_{\mathrm{x}} \mathrm{Fe}_{2-\mathrm{x}} \mathrm{O}_{4}$ nano ferrites $(0.00 \leq \mathrm{x} \leq 0.25)$.

\begin{tabular}{ccccccc}
\hline Composition $(\mathrm{X})$ & $\mathrm{Ms}(\mathrm{emu} / \mathrm{g})$ & $\mathrm{Mr}(\mathrm{emu} / \mathrm{g})$ & $\mathrm{Hc}(\mathrm{Oe})$ & $\mathrm{K}(\mathrm{erg} / \mathrm{Oe})$ & $\mathrm{Mr} / \mathrm{Ms}$ & $\mu_{\mathrm{B}}$ \\
\hline 0.00 & 63.52 & 34.34 & 1590.40 & $103.09 \times 10^{3}$ & 0.5406 & 2.66 \\
0.05 & 61.04 & 33.73 & 1538.46 & $95.82 \times 10^{3}$ & 0.5526 & 2.64 \\
0.10 & 60.80 & 30.21 & 1302.88 & $80.84 \times 10^{3}$ & 0.4969 & 2.72 \\
0.15 & 50.11 & 26.21 & 1192.30 & $60.96 \times 10^{3}$ & 0.5231 & 2.31 \\
0.20 & 49.97 & 23.61 & 966.346 & $49.27 \times 10^{3}$ & 0.4725 & 2.37 \\
0.25 & 48.73 & 22.97 & 927.88 & $46.14 \times 10^{3}$ & 0.4714 & 2.38 \\
\hline
\end{tabular}

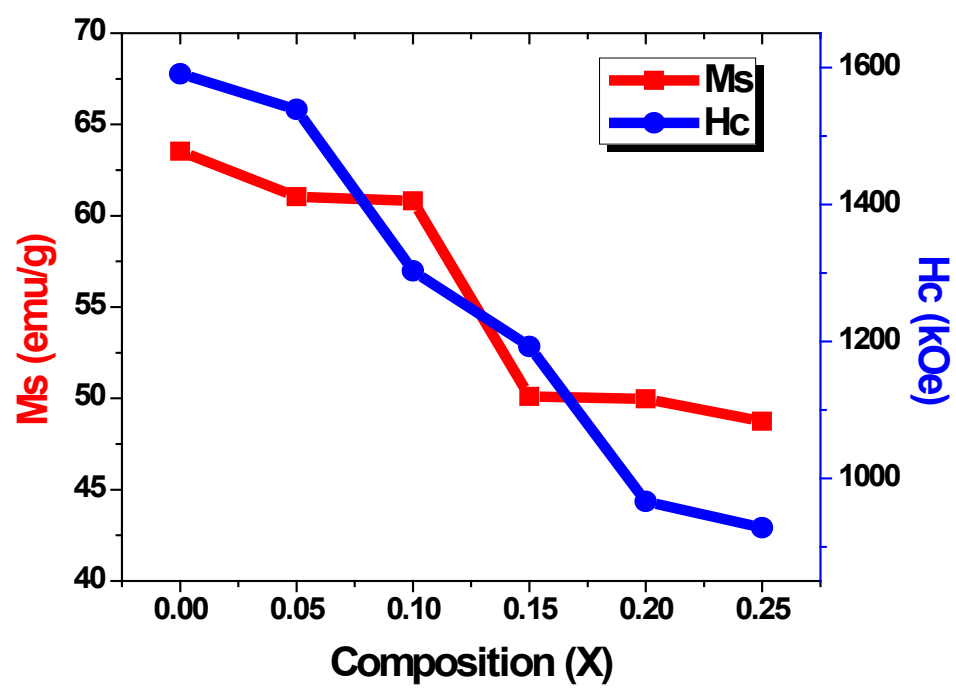

Figure 4. The relative variation of saturation magnetisation (Ms) and applied magnetic field $(\mathrm{Hc})$ with doping concentration $(\mathrm{x})$ of the composition of $\mathrm{CoBi}_{\mathrm{x}} \mathrm{Fe}_{2-\mathrm{x}} \mathrm{O}(0.00 \leq \mathrm{x} \leq 0.25)$.

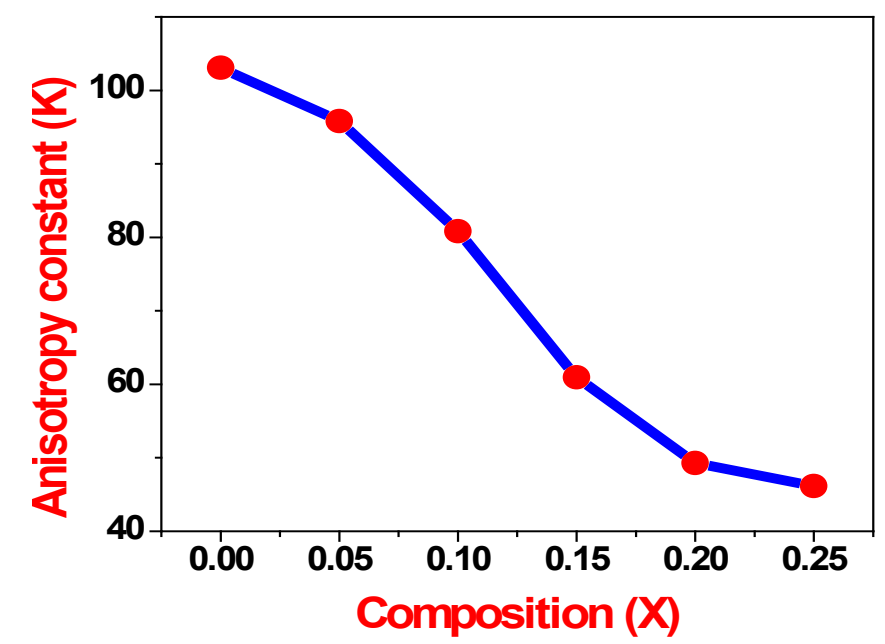

Figure 5. The variation of anisotropic constant $(\mathrm{K})$ with the $\mathrm{Bi}^{3+}$ ion concentration (x) $\mathrm{CoBi}_{\mathrm{x}} \mathrm{Fe}_{2-\mathrm{x}} \mathrm{O}(0.00 \leq \mathrm{x} \leq 0.25)$.

the net magnetic moment of the composition is given as $M=M_{B}-M_{A}$, where $M_{B}$ and $M_{A}$ are the magnetic moment of $\mathrm{B}$ and $\mathrm{A}$ sub lattices respectively. It is also observed from Table 1 the coercivity values are gradually decreasing with increase of bismuth content, due to the decrease in magneto crystalline anisotropy $(\mathrm{K})$. As 
compared with greater magneto crystalline anisotropy of iron with bismuth is having negative magneto crystalline anisotropy [29], therefore the values of anisotropy and coercivity were decreasing with the increase of bismuth content. The correlation of saturation magnetisation and coercivity is clearly shown in Figure 4. A similar work was observed in the literature [27] [29]. The anisotropy of the composition can be evaluated by the formula $\mathrm{K}=\mathrm{Hc} \times \mathrm{Ms} / 0.98$ and the values are tabulated in Table 1 . From Figure 5 it is clear that the anisotropy is decreasing with the increasing of $\mathrm{Bi}^{3+}$ ion concentration and which leads the decrease in magneto static energy [31] [32].

Sqareness ratio or remnant ratio $(\mathrm{Mr} / \mathrm{Ms})$ of a material is one of the important characteristic which depends on its anisotropy. The values of squreness ratio represent the random arrangement of uniaxial particles along with the cubic magneto crystalline anisotropy [33] [34].

In the present work the squreness ratio of pure $\mathrm{CoFe}_{2} \mathrm{O}_{4}$ is 0.54 at room temperature and which was decreased to 0.47 with the increase of bismuth ion concentration. And it has been observed from literature that the squreness ratio is less than 0.6 , which indicate the presence of non interacting single domain particles with cubic anisotropy in the respective compositions [35]. The values of Bohr Magneton $\left(\mu_{B}\right)$ of these samples were also evaluated by using the following Equation (3).

$$
\mu_{B}=\frac{M_{S} M_{W}}{5585}
$$

where: $M_{w}$ is molecular weight of the sample; $M_{s}$ is saturation magnetisation.

$5585=\beta \times N\left[\beta\right.$ is Conversion factor $\left(9.27 \times 10^{-21}\right) ; N$ is Avogadro's number $]$.

It is observed from Table 1 that Bohr Magneton values are gradually decreased from 2.668 to 2.381. With the research interest one can modified the compositions of ferrite materials in accordance with sqareness ratio (S), for the development of new electromagnetic materials [29]. In the present work it is observed a clear variation on magnetic properties of bismuth doped cobalt ferrite nano particles.

\section{Conclusion}

The metal nitrates of cobalt ferrite with fine doping of bismuth powders have been synthesised successfully by sol-gel combustion method. With the XRD results it is confirmed that the spinal structure of $\mathrm{CoFe}_{2} \mathrm{O}_{4} \mathrm{exhibits}$ single phase fcc structure, which is not modified by bismuth ion substitution in small amount. The TEM images show the morphology and particle size of the prepared samples at different magnifications. It is observed that the magnetic properties Ms, Mr, and Hc are decreasing with the increase of bismuth ion concentration. The decrease in anisotropy $(\mathrm{K})$ and sqareness ratio $(\mathrm{S})$ is suggesting that, the existence of non-conducting domain particles is in accordance with the doping concentration. The obtained Bohr Magneton $\left(\mu_{B}\right)$ values also follow the decrease in trend with the increase of doping concentration.

\section{Acknowledgements}

The author NSK is thankful to Dr. K.E. Balachandrudu, Principal, MRIET, Secunderabad for providing the necessary facilities to bring out this research work. Dr. KVK is grateful to Prof. N. V. Ramana, Principal, JNTUH College of Engineering Jagtial, Nachupally (Kondagattu), Karimnagar-Dist for his encouragement.

\section{References}

[1] Slunkhe, A.B., Khot, V.M., Phadatare, M.R., et al. (2014) Low Temperature Combustion Synthesis and Magnetostructural Properties of Co-Mn Nanoferrites. Journal of Magnetic Materials, 352, 91-98. http://dx.doi.org/10.1016/i.jmmm.2013.09.020

[2] Zhao, D., Wu, X., Guan, H. and Han, E. (2007) Study on Super Critical Hydrothermal Synthesis of CoFe2O4 Nano Particles. Journal of Super Critical Fluids, 42, 226-233. http://dx.doi.org/10.1016/j.supflu.2007.03.004

[3] Zhang, Y., Liu, Y., Fei, C., Yang, Z., Lu, Z., Xiong, R., Yin, D. and Shi, J. (2010) The Temperature Dependence of Magnetic Properties for Cobalt Ferrite Nano Particles by the Hydrothermal Method. Journal of Applied Physics, 108, Article IA: 084312. http://dx.doi.org/10.1063/1.3499289

[4] Biswal, D., Peeples, B.N., Peeples, C. and Pradhan, A.K. (2013) Tuning of Magnetic Properties in Cobalt Ferrite by Varying $\mathrm{Fe}^{+2}$ and $\mathrm{Co}^{+2}$ Molar Ratios. Journal of Magnetism and Magnetic Materials, 345, 1-6. http://dx.doi.org/10.1016/j.jmmm.2013.05.052 
[5] Kuckelhaus, S., Reis, S.C., Carniero, M.F., Todesco, A.C., Oliveira, D.M., Lima, E.C., Morais, P.C., Azevedo, R.B. and Lacava, Z.G.M. (2004) In Vivo Investigation of Cobalt Ferrite Based Magnetic Fluid and Magnetoliposomes Using Morphological Tests. Journal of Magnetism and Magnetic Materials, 2402, 272.

[6] Tung, L.D., Kolesnichenko, V.L., Caruntu, D., Chou, N.H., O’Connor, C.J. and Spinu, C.J.L. (2003) Magnetic Properties of Ultrafine Cobalt Ferrite Particles. Journal of Applied Physics, 93, 7486. http://dx.doi.org/10.1063/1.1540145

[7] Hanh, N., Quy, O.K., Thuy, N.P., Tung, L.D. and Spinu, L. (2003) Synthesis of Cobalt Ferrite Nanocrystallites by the Forced Hydrolysis Method and Investigation of Their Magnetic Properties. Physica B: Condensed Matter, 327, $382-$ 384. http://dx.doi.org/10.1016/S0921-4526(02)01750-7

[8] Amighian, J., Mozaffari, M. and Nasr, B. (2006) Preparation of Nano-Sized Manganese Ferrite (Mn-Fe2O4) via Coprecipitation Method. Journal of Solid State Physics, 3, 3188-3192.

[9] Meenakshisundaram, A., Gunasekaran, N. and Srinivasan, V. (1982) Distribution of Metal Ions in Transition Metal Manganites AMn2O4 (A: Co, Ni, Cu, or Zn). Physica Status Solidi(a), 69, K15-K19. http://dx.doi.org/10.1002/pssa.2210690149

[10] Pallai, V. and Shah, D.O. (1996) Synthesis of High-Coercivity Cobalt Ferrite Particles Using Water-in-Oil Microemulsions. Journal of Magnetism and Magnetic Materials, 163, 243-248. http://dx.doi.org/10.1016/S0304-8853(96)00280-6

[11] Skomski, R. (2003) Nanomagnetics. Journal of Physics: Condensed Matter, 15, R841-R896. http://dx.doi.org/10.1088/0953-8984/15/20/202

[12] Shenoy, S.D., Joy, P.A., Anantharaman, M.R. and Magn, J. (2004) Effect of Mechanical Milling on the Structural, Magnetic and Dielectric Properties of Coprecipitated Ultrafine Zinc Ferrite. Journal of Magnetism and Magnetic Materials, 269, 217-226. http://dx.doi.org/10.1016/S0304-8853(03)00596-1

[13] Jiang, J.Z., Wynn, P., Morup, S., Okada, T. and Berry, F.J. (1999) Magnetic Structure Evolution in Mechanically Milled Nanostructured $\mathrm{ZnFe}_{2} \mathrm{O}_{4}$ Particles. Nanostructured Materials, 12, 737-740. http://dx.doi.org/10.1016/S0965-9773(99)00228-7

[14] Atif, M., Hasanain, S.K. and Nadeem, M. (2006) Magnetization of Slo-Gel Prepared Zinc Ferrite Nano Particles. Journal of Science Communication, 138, 416-421.

[15] Hamdeh, H.H., Ho, J.C., Oliver, S.A., Willey, R.J., Oliveri, G. and Busca, G. (1997) Magnetic Properties of Partially-Inverted Zinc Ferrite Aerogel Powders. Journal of Applied Physics, 81, 1851-1858. http://dx.doi.org/10.1063/1.364068

[16] Yu, S.H., Fujino, T. and Yoshimura, M. (2003) Hydrothermal Synthesis of $\mathrm{ZnFe}_{2} \mathrm{O}_{4}$ Ultrafine Particles with High Magnetization. Journal of Magnetism and Magnetic Materials, 256, 420-424. http://dx.doi.org/10.1016/S0304-8853(02)00977-0

[17] Naseri, M.G., Saion, E.B. and Hashim, M. (2011) Synthesis and Characterization of Zinc Ferrite Nanoparticles by a Thermal Treatment Method. Solid State Communications, 151, 1031-1035. http://dx.doi.org/10.1016/j.ssc.2011.04.018

[18] Pallai, V. and Shah, D.O. (1996) Synthesis of High-Coercivity Cobalt Ferrite Particles Using Water-in-Oil Microemulsions. Journal of Magnetism and Magnetic Materials, 163, 243-248. http://dx.doi.org/10.1016/S0304-8853(96)00280-6

[19] Brinker, C.J. and Scherer, G.W. (1990) Sol-Gel Science: The Physics and Chemistry of Sol-Gel Processing. Academic Press, San Diego.

[20] Bensebaa, F., Zavaliche, F., L'Ecuyer, P., Cochrane, R.W. and Veres, T. (2004) Microwave Synthesis and Characterization of Co-Ferrite Nanoparticles. Journal of Colloid and Interface Science, 277, 104-110. http://dx.doi.org/10.1016/j.jcis.2004.04.016

[21] Nasr Isfahani, M.J. and Fesharaki, M.J. (2013) Magnetic Behavior of Nickel-Bismuth Ferrite Synthesized by a Combined Sol-Gel/Thermal Method. Ceramics International, 39, 1163-1167. http://dx.doi.org/10.1016/j.ceramint.2012.07.040

[22] Srinivas, V., Raghavender, A.T. and Vijaya Kumar, K. (2016) Effect of Ba Substitution on the Structural and Magnetic Properties of $\mathrm{BiFeO}_{3}$. World Journal of Nano Science and Engineering, 6, 38-44. http://dx.doi.org/10.4236/wjnse.2016.61004

[23] Arulmurugan, R., Jeyadevan, B., Vaidyanathan, G. and Sendhilnathan, S. (2005) Effect of Zinc Substitution on Co-Zn and Mn-Zn Ferrite Nanoparticles Prepared by Co-Precipitation. Journal of Magnetism and Magnetic Materials, 288, 470-477. http://dx.doi.org/10.1016/j.jmmm.2004.09.138

[24] Maaz. K. and Mumtaz. A. (2007) Synthesis and Magnetic Properties of Cobalt Ferrite $\left(\mathrm{CoFe}_{2} \mathrm{O}_{4}\right)$ Nanoparticles Prepared by Wet Chemical Route. Journal of Magnetism and Magnetic Materials, 308, 289-295. http://dx.doi.org/10.1016/j.jmmm.2006.06.003

[25] Singhal, S., Jauhar, S., Lakshmi, N. and Bansal, S. (2013) Mn3 ${ }^{+}$Substituted Co-Cd Ferrites, $\operatorname{CoCd}_{0.4} \mathrm{Mn}_{x} \mathrm{Fe}_{1.6-x} \mathrm{O}_{4}(0.1$ $\leq x \leq 0.6)$ : Cation Distribution, Structural, Magnetic and Electrical Properties. Journal of Molecular Structure, 1038, 
45-51. http://dx.doi.org/10.1016/j.molstruc.2013.01.020

[26] Miller, A. (1995) Journal of Applied Physics, 30, 245.

[27] Singhal, S. and Jauhar, S. (2012) Investigation of Structural, Magnetic, Electrical and Optical Properties of Chromium Substituted Cobalt Ferrites $\left(\mathrm{CoCr}_{x} \mathrm{Fe}_{2-x} \mathrm{O}_{4}, 0 \leq x \leq 1\right)$ Synthesized Using Sol Gel Auto Combustion Method. Journal of Molecular Structure, 1012, 182-188. http://dx.doi.org/10.1016/j.molstruc.2011.12.035

[28] Singhal, S., Barthwal, S.K. and Chandra, K. (2006) XRD, Magnetic and Mössbauer Spectral Studies of Nano Size Aluminum Substituted Cobalt Ferrites $\left(\mathrm{CoAl}_{x} \mathrm{Fe}_{2-x} \mathrm{O}_{4}\right)$. Journal of Magnetism and Magnetic Materials, 306, $233-340$. http://dx.doi.org/10.1016/j.jmmm.2006.03.023

[29] Bhukal, S., Namgyal, T., Mor, S., Bansal, S. and Singhal, S. (2012) Structural, Electrical, Optical and Magnetic Properties of Chromium Substituted Co-Zn Nanoferrites $\mathrm{Co}_{0.6} \mathrm{Zn}_{0.4} \mathrm{Cr}_{x} \mathrm{Fe}_{2-x} \mathrm{O}_{4}(0 \leq x \leq 1.0)$ Prepared via Sol-Gel Auto-Combustion Method. Journal of Molecular Structure, 1012, 162-167. http://dx.doi.org/10.1016/j.molstruc.2011.12.019

[30] Smart, J.S. (1955) The Néel Theory of Ferrimagnetism. American Journal of Physics, 23, 356-370. http://dx.doi.org/10.1119/1.1934006

[31] Gul, I.H., Abbasi, A.Z., Amin, F., Rehman, M.A. and Maqsood, A. (2007) Structural, Magnetic and Electrical Properties of $\mathrm{Co}_{1-x} \mathrm{Zn}_{x} \mathrm{Fe}_{2} \mathrm{O}_{4}$ Synthesized by Co-Precipitation Method. Journal of Magnetism and Magnetic Materials, 311, 494-499. http://dx.doi.org/10.1016/j.jmmm.2006.08.005

[32] Bueno. A.R, Gregori. I.M. and Nobrega. M.C.S. (2007) Effect of Mn Substitution on the Microstructure and Magnetic Properties of $\mathrm{Ni}_{0.50-x} \mathrm{Zn}_{0.50-x} \mathrm{Mn}_{2 x} \mathrm{Fe}_{2} \mathrm{O}_{4}$ Ferrite Prepared by the Citrate-Nitrate Precursor Method. Materials Chemistry and Physics, 105, 229-233. http://dx.doi.org/10.1016/j.matchemphys.2007.04.047

[33] Raut, A.V., Barkule, R.S., Shengule, D.R. and Jadhav, K.M. (2014) Synthesis, Structural Investigation and Magnetic Properties of $\mathrm{Zn}^{2+}$ Substituted Cobalt Ferrite Nanoparticles Prepared by the Sol-Gel Auto-Combustion Technique. Journal of Magnetism and Magnetic Materials, 358, 87-92. http://dx.doi.org/10.1016/j.jmmm.2014.01.039

[34] Berkowwitz, A.E. and Kneller, E. (1654) Magnetism and Metallurgy. Vol. 1, Academic Press, New York, 295.

[35] Ibusuki, T., Kojima, S., Kitakami, O. and Shimada, Y. (2001) Magnetic Anisotropy and Behaviors of Fe Nanoparticles. IEEE Transactions on Magnetics, 37, 2223-2225. http://dx.doi.org/10.1109/20.951130

\section{Submit or recommend next manuscript to SCIRP and we will provide best service for you:}

Accepting pre-submission inquiries through Email, Facebook, Linkedin, Twitter, etc A wide selection of journals (inclusive of 9 subjects, more than 200 journals)

Providing a 24-hour high-quality service

User-friendly online submission system

Fair and swift peer-review system

Efficient typesetting and proofreading procedure

Display of the result of downloads and visits, as well as the number of cited articles

Maximum dissemination of your research work

Submit your manuscript at: http://papersubmission.scirp.org/ 